\title{
Long term influence of insulin dependent diabetes mellitus on refraction and its components: a population based twin study
}

\author{
Niels Løgstrup, Anne Katrin Sjølie, Kirsten Ohm Kyvik, Anders Green
}

\begin{abstract}
Aim-To study whether refraction of the eye, or some of its components is influenced by duration of insulin dependent diabetes mellitus.

Methods-From the young cohort of the population based Danish Twin Register, containing 20888 twin pairs born between 1953 and 1982, all twin pairs having one or both partners affected with IDDM were searched. Autorefraction, autokeratometry, and ultrasonic biometric measurements were carried out on 45 twin pairs: 16 monozygotic (MZ) twin pairs, 14 dizygotic twin pairs of same sex (DZss), and 15 dizygotic twin pairs of opposite sex (DZos). To obtain an estimate of the influence of duration of diabetes, the intrapair differences in duration of diabetes were correlated with intrapair differences in refraction and each of its components.

Results-Refraction was statistically significantly negatively correlated with duration of diabetes in the DZss group, and axial length correspondingly positively correlated. Surprisingly, refraction and axial length in the $M Z$ group, adjusted for confounding factors, were correlated with diabetes duration in the opposite direction than in the DZss group, although not reaching statistical significance. Lens thickness was statistically significantly positively correlated with duration of diabetes in both $M Z$ and $\mathrm{DZ}$ twins. Anterior chamber depth was negatively correlated with duration of diabetes in all the zygosity groups.

Conclusions-Studies of relations between refraction and duration of diabetes show diverging results. In the $M Z$ group, a tendency to reduced axial length and corresponding hyperopia with increasing duration of diabetes was found. However, in the DZ group of same sex the opposite tendency was found. Increasing lens thickness and decreasing anterior chamber depth with increasing duration of diabetes have been confirmed in this study. (Br F Ophthalmol 1997;81:343-349)
\end{abstract}

Refraction and its components are influenced by both environmental and inherited factors. Twin studies have earlier described the importance of genes in refraction, by high concordance rates of refraction in monozygotic twins compared with dizygotic twins. ${ }^{1-5}$ In contrast with this, lower heritability of myopia has been reported in a newer Italian twin study on children, ${ }^{6}$ in which different axial lengths and corresponding different refractive values were found in several twins pairs, and this was related to different degrees of visual deprivation. Axial length is the most important determinant of refractive power. ${ }^{7}$ Moreover, in cases with adult onset of myopia, an increase in axial length was found to be the main factor responsible. ${ }^{8-10}$ Even with some variations in axial length, optical power can remain the same. ${ }^{11}$

Insulin dependent diabetes mellitus (IDDM) may affect refraction with short term fluctuations and more permanent alterations. ${ }^{12}$ The generally accepted view is that short term fluctuations alter the refraction of the lens, primarily by alterations in osmotic pressure caused by changes in the blood glucose level and accumulation of sorbitol and fructose in the lens by the sorbitol pathway. No general agreement has been reached regarding the direction of these refractive changes. ${ }^{13}$ It has been suggested that there is a higher degree of myopia when there is a high blood glucose level, and a hyperopic shift when the blood glucose level normalises. ${ }^{14}{ }^{15}$ Other studies, however, suggest alterations in a hyperopic direction at high blood glucose levels, ${ }^{16-18}$ as confirmed in animal studies. ${ }^{19}$

With regard to the more permanent alterations in refraction with duration of diabetes there are fewer studies. An increased prevalence of low degree myopia among diabetic compared with non-diabetic patients has been found by some authors. ${ }^{20-22}$ Rand et al ${ }^{23}$ found a higher prevalence of myopia among diabetic patients with retinopathy compared with diabetic patients without retinopathy. Jain et al ${ }^{24}$ found no difference in prevalence of myopia in diabetic versus non-diabetic subjects, although diabetic patients with higher myopia were less likely to develop retinopathy. 
Duration of IDDM has earlier been shown to have a clear influence on lens thickness ${ }^{25-27}$ confirmed in our own twin study. ${ }^{28}$ Whether the increased lens thickness is responsible for the observed higher prevalence of low degree myopia among diabetics remains unclear, especially as the refractive index of the lens is altered at the same time. Since lens thickness increases with age, separating the effect of duration of diabetes from that of increasing age is difficult.

Investigations in twins offer unique opportunities for eliminating the effects of age and other confounding factors in studies of the association between diabetes duration and refraction and its components. Partners of monozygotic (MZ) twin pairs are genetically identical and matched for age and most environmental influences that determine growth and development. Partners of dizygotic (DZ) twin pairs have the same features but share only $50 \%$ of their genes on average. We used the twin control method in a modified version, where the intrapair differences in exposures (for example, diabetes duration) and outcomes (for example, refraction and its components) were calculated. In this way confounding factors can be eliminated in the assessment of a possible association between exposure and outcome.

We report here the results of a twin control study of the association between duration of IDDM and refraction and its components. The twin pairs have been ascertained from the new part of the Danish Twin Register ${ }^{29}$ as part of a larger twin study on IDDM. ${ }^{30}$

\section{Materials and methods}

THE TWIN SAMPLE

The new part of the Danish Twin Register includes 20888 twin pairs, born in Denmark between 1953 and 1982 (inclusive). It has been established on the basis of the Danish Civil Registration System and is considered to be a representative sample comprising $74.4 \%$ of all Danish twin pairs born between 1953 and 1967 , and virtually complete $(97.4 \%)$ concerning twin pairs born between 1968 and1982. ${ }^{29}$ Among 19180 twin pairs responding to a questionnaire survey on IDDM, ${ }^{30} 102$ pairs had one or both partners affected with IDDM.

Table 1 Summary of study material

\begin{tabular}{lr}
\hline Twin pairs born 1953-82 registered in the & \\
new Danish Twin Register & 20888 \\
Twin pairs with IDDM identified by & 102 \\
questionnaire: & 39 \\
One or both unwilling to participate & 7 \\
One twin partner had died & 5 \\
One twin partner had emigrated & 3 \\
$\quad$ No response in one twin partner & 48 \\
Twin pairs investigated: 17 MZ pairs, 15 & \\
$\quad$ DZss pairs, and 16 DZos pairs & 1 \\
Twin pairs excluded from paired analysis: & 1 \\
$\quad$ Did not want pupils dilated (MZ) & \\
Ocular trauma in one eye (DZos) & 1 \\
Corneal transplantation in one eye & \\
(DZss) & \\
Twin pairs in paired analysis: $16 \mathrm{MZ} \mathrm{,} \mathrm{14}$ & 45 \\
DZss, and 15 DZos pairs & \\
\hline
\end{tabular}

$\star$ Of these, two twins $(M Z+D Z s s)$ did not cooperate with ultrasonic measurements.
Of these, 54 pairs were not available for further examination (Table 1).

Forty eight pairs were investigated; of these, three pairs were excluded. In the $M Z$ group, one pair did not want their pupils dilated, and declined further examination. In the DZss group, one twin had an earlier corneal transplantation in one eye after herpes infection, and in the DZos group one eye was aphakic after trauma, and the fellow eye had become highly myopic (-14 D) with an axial length of $27.67 \mathrm{~mm}$. Of the 45 remaining pairs, one 12 year old $\mathrm{MZ}$ twin, and one 15 year old DZss twin did not cooperate with the ultrasonic measurements, leaving 43 pairs for all the paired analysis in the present study (Table 1).

The zygosity diagnosis was established on 11 blood and enzyme type systems, providing a more than $99 \%$ reliable classification. ${ }^{29}$ The diagnosis of IDDM has been based on internationally accepted clinical criteria combined with no or low fasting C peptide. ${ }^{30}$ Onset of diabetes was defined as the month and year when the first insulin injection was given. The actual level of metabolic control was evaluated from measurement of glycosylated haemoglobin $\left(\mathrm{HbA}_{1 \mathrm{c}}\right)$ and blood glucose performed approximately 3 hours before the ophthalmic examination. The twins were interviewed about their habits of reading and close work and the approximate number of hours per day were registered. Education was divided into four levels: 1, primary school ( $\leqslant 9$ years); 2 , secondary school (10-13 years); 3, college or technical education (14-17 years); 4, university education ( $>17$ years).

OPHTHALMIC MEASUREMENTS

Visual acuity with best correction before cycloplegia was recorded. Power of own glasses or contact lenses was measured. Cycloplegia was obtained by instillation of one drop of cyclopentolate hydrochloride $1 \%$ and one drop of phenylephrine hydrochloride $10 \%$ in each eye, twice, with an interval of 10 minutes. Refraction and keratometry were carried out on a Canon RF-2 autorefraction keratometer at least 30 minutes after the last cycloplegic drop, and the mean of five measurements was taken. Axial length (AL), anterior chamber depth (ACD), and lens thickness (LT) were measured by ultrasonography on a Teknar Ophthasonic Auto A Scan. The mean of three measurements was taken. Speed of ultrasound was set to $1532 \mathrm{~m} / \mathrm{s}$ for aqueous and vitreous and $1641 \mathrm{~m} / \mathrm{s}$ for the lens. The ultrasound device was calibrated on a special calibration probe several times during the investigation period. All measurements were performed on the same device and by the same trained ophthalmologist (NL). Only measurements with narrow and well defined echoes of equal height from anterior and posterior lens surfaces and with no internal spikes, and well defined echo from the vitreoretinal interface were accepted, to obtain correct measurement of lens thickness and to ensure correct alignment and axial direction of the measurements. Lenses were examined for cataract by slit-lamp examination in mydriasis, and photographs of the lenses in 
retroillumination were taken for documentation of lens opacities. None of the investigated twins had cataract. Ten of the diabetic twins and two of the non-diabetic twins had a few vacuoles peripherally in the lenses of both eyes.

ANALYSIS OF DATA

The spherical equivalent of refraction was calculated as spherical value plus half of the negative cylinder value. The radius of corneal curvature (CC) was calculated as the average of the curvature in the two main meridians. Lens power (LPW) was calculated with the Catrefract ${ }^{31}$ computer program $^{32}$ on the basis of refraction in cycloplegia, corneal curvature, and biometry of anterior chamber depth, lens thickness, and axial length. This was performed to obtain an estimate of refractive index of the lens.

To obtain an estimate of the influence of duration of diabetes, the intrapair differences of duration of diabetes were correlated with intrapair differences in refractive values and their components. The partner with longer duration of IDDM was labelled A, and the partner with shorter duration or no IDDM was labelled B. Unaffected twins were assigned the value of 0.0 years of IDDM duration. Within each twin pair the difference in IDDM duration was calculated, as the difference in duration, between twin $\mathrm{A}$ and twin $\mathrm{B}(\mathrm{A}-\mathrm{B})$. The corresponding intrapair differences in refraction and refractive components were calculated, for right and left eye separately. Because the three groups were small, we chose the non-parametric Spearman correlation coefficients in the statistical analysis of our results in the three zygosity groups. To search for the possible confounders, close work and education, the intrapair differences of these variables were calculated as described above. To obtain an estimate of the influence on refraction on any acute dysregulation of diabetes the difference between power of the twins' own glasses and the actual refraction was calculated and this was correlated with the measured values of $\mathrm{HbA}_{1 \mathrm{c}}$ and blood glucose.

Table 2 Results from all the investigated twins divided in the three zygosity groups: $M Z$, monozygotic twins, DZss, dizygotic twins of same sex, DZos, dizygotic twins of opposite sex

\begin{tabular}{|c|c|c|c|c|c|c|c|c|c|c|c|}
\hline \multirow{2}{*}{$\begin{array}{l}\text { Twin pair } \\
\text { No }\end{array}$} & \multirow{2}{*}{$\begin{array}{l}\text { Age } \\
\text { (years) }\end{array}$} & \multirow[b]{2}{*}{$\operatorname{Sex}$} & \multicolumn{3}{|c|}{ Duration of diabetes ${ }^{*}$ (years) } & \multicolumn{2}{|c|}{$H b A_{1 c}(\%)$} & \multicolumn{2}{|c|}{ Blood glucose $(\mathrm{mmol} / \mathrm{l})$} & \multirow{2}{*}{$\begin{array}{l}\begin{array}{l}\text { Read time } \\
\text { (hours) }\end{array} \\
A-B\end{array}$} & \multirow{2}{*}{$\begin{array}{l}\begin{array}{l}\text { Education } \\
\text { (level) }\end{array} \\
A-B\end{array}$} \\
\hline & & & $A$ & $B$ & $A-B$ & $A$ & $B$ & $A$ & $B$ & & \\
\hline \multicolumn{12}{|l|}{ MZ: } \\
\hline 1 & 14.8 & $M$ & 0.2 & & 0.2 & 7.8 & 7.6 & 10.1 & 10.8 & 0 & 0 \\
\hline 2 & 39.7 & $M$ & 17.6 & 16.6 & 1.0 & 11.6 & 14.0 & 4.7 & 5.3 & 0 & $\neq$ \\
\hline 3 & 25.3 & M & 3.0 & & 3.0 & 8.0 & 6.7 & 14.0 & 10.3 & 0 & 0 \\
\hline 4 & 36.8 & M & 3.4 & 0.3 & 3.1 & 10.7 & 8.7 & 7.3 & 6.4 & 0 & 0 \\
\hline 5 & 24.5 & $\mathrm{~F}$ & 3.4 & . & 3.4 & 6.1 & 5.5 & 16.4 & 6.1 & 0 & 0 \\
\hline 6 & 31.7 & M & 18.9 & 15.1 & 3.8 & 8.1 & 7.5 & 14.5 & 14.8 & 0 & 0 \\
\hline 7 & 36.8 & M & 13.9 & 9.1 & 4.8 & 8.3 & 6.9 & $\neq$ & $\neq$ & 1 & 0 \\
\hline 8 & 25.2 & M & 5.7 & . & 5.7 & 10.5 & 6.5 & 6.1 & 5.2 & 0 & 0 \\
\hline 9 & 30.1 & $\mathrm{~F}$ & 6.0 & & 6.0 & 9.3 & 6.3 & 4.9 & 4.4 & 0 & 1 \\
\hline 10 & 31.0 & M & 13.8 & 5.8 & 8.0 & 11.0 & 12.0 & 12.2 & 14.2 & 1 & 1 \\
\hline 11 & 11.7 & $M$ & 8.7 &. & 8.7 & 9.8 & 5.3 & 8.4 & 4.6 & 0 & 0 \\
\hline 12 & 32.2 & M & 17.2 & 7.1 & 10.1 & 9.4 & 9.5 & 5.6 & 4.6 & -1 & -3 \\
\hline 13 & 19.9 & $\mathrm{~F}$ & 10.7 & . & 10.7 & 12.8 & 5.6 & 16.6 & 5.1 & 0 & 0 \\
\hline $14 \dagger$ & 12.7 & M & 10.8 & . & 10.8 & 11.0 & 7.5 & 7.1 & 5.6 & 0 & 0 \\
\hline 15 & 38.5 & $\mathrm{~F}$ & 26.7 & . & 26.7 & 7.1 & 5.9 & 8.9 & 6.8 & 0 & -1 \\
\hline 16 & 35.0 & M & 30.1 & . & 30.1 & 9.5 & 6.2 & 13.5 & 5.2 & 0 & 0 \\
\hline \multicolumn{12}{|l|}{ DZss: } \\
\hline $1 \dagger$ & 15.3 & $\mathrm{~F}$ & 0.5 & . & 0.5 & 5.4 & 6.7 & 10.3 & 5.0 & -1 & 0 \\
\hline 2 & 25.8 & M & 2.0 & . & 2.0 & 6.1 & 6.2 & 8.7 & 5.1 & -3 & -2 \\
\hline 3 & 37.1 & $\mathrm{~F}$ & 2.6 & . & 2.6 & 8.7 & 5.6 & 13.3 & 4.7 & -4 & -2 \\
\hline 4 & 29.2 & $\mathrm{~F}$ & 3.2 & . & 3.2 & 9.6 & 7.5 & 8.0 & 5.6 & 2 & 2 \\
\hline 5 & 37.6 & $\mathrm{M}$ & 3.6 & . & 3.6 & 7.2 & 6.6 & 5.7 & 9.6 & 0 & 0 \\
\hline 6 & 34.4 & $\mathrm{~F}$ & 3.8 & . & 3.8 & 9.9 & 5.9 & 14.4 & 5.5 & 0 & 0 \\
\hline 7 & 37.3 & M & 4.0 & . & 4.0 & 7.0 & 5.6 & 15.3 & 4.3 & 2 & 3 \\
\hline 8 & 11.6 & $\mathrm{~F}$ & 4.6 & . & 4.6 & 6.2 & 6.0 & 8.6 & 5.0 & -1 & 0 \\
\hline 9 & 35.6 & M & 6.8 & . & 6.8 & 10.8 & 5.7 & 3.4 & 5.1 & 0 & -1 \\
\hline 10 & 34.8 & M & 11.2 & . & 11.2 & 9.9 & 6.6 & 16.9 & 4.8 & -1 & 0 \\
\hline 11 & 16.8 & $\mathrm{~F}$ & 12.6 & . & 12.6 & 12.7 & 6.5 & 10.0 & 5.1 & 0 & 0 \\
\hline 12 & 24.1 & M & 13.8 & . & 13.8 & 8.5 & 6.3 & 15.9 & 4.6 & 1 & 0 \\
\hline 13 & 18.3 & $\mathrm{~F}$ & 14.4 & . & 14.4 & 10.1 & 6.1 & 5.2 & 5.0 & 0 & 0 \\
\hline 14 & 20.7 & $\mathrm{~F}$ & 15.7 & . & 15.7 & 11.6 & 5.5 & 4.0 & 5.8 & 0 & 0 \\
\hline \multicolumn{12}{|l|}{ DZos: } \\
\hline 1 & 22.8 & $\mathrm{~F} / \mathrm{M}$ & 2.3 & . & 2.3 & 12.9 & 6.6 & 15.4 & 5.0 & 2 & 0 \\
\hline 2 & 27.5 & $\mathrm{~F} / \mathrm{M}$ & 2.6 & . & 2.6 & 11.1 & 7.2 & 9.7 & 4.8 & 5 & 3 \\
\hline 3 & 32.9 & $\mathrm{~F} / \mathrm{M}$ & 2.8 & . & 2.8 & 7.4 & 5.5 & 22.6 & 7.8 & -1 & -2 \\
\hline 4 & 31.4 & $\mathrm{~F} / \mathrm{M}$ & 4.9 & . & 4.9 & 8.5 & 5.6 & 4.2 & 4.9 & 2 & 2 \\
\hline 5 & 26.0 & $\mathrm{M} / \mathrm{F}$ & 5.7 & . & 5.7 & 6.5 & 5.7 & 7.7 & 5.8 & -1 & -1 \\
\hline 6 & 22.4 & $\mathrm{~F} / \mathrm{M}$ & 7.3 & . & 7.3 & 8.5 & 6.8 & 14.1 & 5.7 & 1 & 1 \\
\hline 7 & 15.1 & $\mathrm{~F} / \mathrm{M}$ & 7.7 & . & 7.7 & 11.4 & 6.1 & 3.1 & 6.2 & 0 & 0 \\
\hline 8 & 14.9 & $\mathrm{M} / \mathrm{F}$ & 7.9 & . & 7.9 & 9.7 & 5.5 & 13.5 & 5.2 & -3 & 0 \\
\hline 9 & 35.5 & $\mathrm{~F} / \mathrm{M}$ & 29.8 & 19.0 & 10.8 & 13.4 & 11.9 & 11.2 & 5.5 & 2 & 4 \\
\hline 10 & 27.9 & $\mathrm{~F} / \mathrm{M}$ & 11.9 & . & 11.9 & 7.4 & 6.2 & 6.4 & 4.9 & -1 & -1 \\
\hline 11 & 26.7 & $\mathrm{M} / \mathrm{F}$ & 14.6 & . & 14.6 & 9.9 & 6.3 & 6.1 & 6.7 & -1 & -2 \\
\hline 12 & 28.8 & $\mathrm{~F} / \mathrm{M}$ & 15.2 & . & 15.2 & 8.5 & 5.7 & 23.3 & 5.5 & 3 & 0 \\
\hline 13 & 30.1 & $\mathrm{~F} / \mathrm{M}$ & 15.9 & . & 15.9 & 10.3 & 6.5 & 16.7 & 5.5 & -1 & 0 \\
\hline 14 & 37.8 & $\mathrm{M} / \mathrm{F}$ & 21.6 & . & 21.6 & 6.3 & 5.7 & 12.9 & 4.7 & 0 & 1 \\
\hline 15 & 38.9 & $\mathrm{~F} / \mathrm{M}$ & 27.0 & . & 27.0 & 5.8 & 8.2 & 15.4 & 5.9 & 0 & 0 \\
\hline
\end{tabular}

*In each pair, the twins with longest duration of diabetes are labelled (A), and the corresponding co-twins with shortest duration or no diabetes (.) are labelled (B). The intrapair differences are labelled $(\mathrm{A}-\mathrm{B})$. 
Table 3 Summary of measured refractive values and refractive components in the group of diabetic twins $(n=52)$ and the group of non-diabetic twins $(n=38)$

\begin{tabular}{|c|c|c|c|c|c|c|c|}
\hline & Eye & $n$ & Mean & Median & $S D$ & Min & $\operatorname{Max}$ \\
\hline \multicolumn{8}{|l|}{ + IDDM: } \\
\hline \multirow[t]{2}{*}{ Refraction (D) } & $\mathrm{R}$ & 52 & -0.63 & -0.25 & 1.92 & -7.75 & 2.75 \\
\hline & $\mathrm{L}$ & 52 & -0.67 & -0.26 & 2.03 & -9.19 & 3.13 \\
\hline \multirow[t]{2}{*}{$\mathrm{AL}(\mathrm{mm})$} & $\mathrm{R}$ & 51 & 23.39 & & 0.95 & 21.55 & 26.09 \\
\hline & $\mathrm{L}$ & 51 & 23.38 & & 1.05 & 21.58 & 26.78 \\
\hline \multirow[t]{2}{*}{$\mathrm{CC}(\mathrm{mm})$} & $\mathrm{R}$ & 52 & 7.76 & & 0.28 & 7.01 & 8.50 \\
\hline & $\mathrm{L}$ & 52 & 7.77 & & 0.29 & 7.04 & 8.42 \\
\hline \multirow[t]{2}{*}{$\mathrm{ACD}(\mathrm{mm})$} & $\mathrm{R}$ & 51 & 3.49 & & 0.31 & 2.89 & 4.04 \\
\hline & $\mathrm{L}$ & 51 & 3.48 & & 0.37 & 2.49 & 4.26 \\
\hline \multirow[t]{2}{*}{$\mathrm{LT}(\mathrm{mm})$} & $\mathrm{R}$ & 51 & 3.88 & & 0.30 & 3.39 & 4.75 \\
\hline & $\mathrm{L}$ & 51 & 3.90 & & 0.35 & 3.20 & 5.18 \\
\hline \multirow[t]{2}{*}{ LPW (D) } & $\mathrm{R}$ & 50 & 24.93 & & 2.09 & 21.13 & 29.93 \\
\hline & $\mathrm{L}$ & 50 & 25.10 & & 2.39 & 20.63 & 32.46 \\
\hline \multicolumn{8}{|l|}{ - IDDM: } \\
\hline \multirow[t]{2}{*}{ Refraction (D) } & $\mathrm{R}$ & 38 & 0.09 & 0.57 & 1.67 & -5.62 & 3.00 \\
\hline & $\mathrm{L}$ & 38 & 0.01 & 0.62 & 1.78 & -6.37 & 2.62 \\
\hline \multirow[t]{2}{*}{$\mathrm{AL}(\mathrm{mm})$} & $\mathrm{R}$ & 37 & 23.37 & & 0.96 & 20.98 & 26.03 \\
\hline & $\mathrm{L}$ & 37 & 23.35 & & 0.99 & 21.53 & 26.25 \\
\hline \multirow[t]{2}{*}{$\mathrm{CC}(\mathrm{mm})$} & $\mathrm{R}$ & 38 & 7.74 & & 0.29 & 7.07 & 8.37 \\
\hline & $\mathrm{L}$ & 38 & 7.71 & & 0.29 & 7.05 & 8.37 \\
\hline \multirow[t]{2}{*}{$\mathrm{ACD}(\mathrm{mm})$} & $\mathrm{R}$ & 37 & 3.62 & & 0.27 & 2.89 & 4.09 \\
\hline & $\mathrm{L}$ & 37 & 3.60 & & 0.27 & 2.94 & 4.03 \\
\hline \multirow[t]{2}{*}{$\mathrm{LT}(\mathrm{mm})$} & $\mathrm{R}$ & 37 & 3.74 & & 0.24 & 3.32 & 4.28 \\
\hline & $\mathrm{L}$ & 37 & 3.76 & & 0.24 & 3.31 & 4.28 \\
\hline \multirow{2}{*}{ LPW (D) } & $\mathrm{R}$ & 36 & 23.87 & & 1.43 & 20.54 & 26.67 \\
\hline & $\mathrm{L}$ & 36 & 23.87 & & 1.51 & 20.50 & 27.47 \\
\hline
\end{tabular}

IDDM = insulin dependent diabetes mellitus; $\mathrm{AL}=$ axial length; $\mathrm{CC}=$ corneal curvature radius; $\mathrm{ACD}=$ anterior chamber depth; LT $=$ lens thickness; $\mathrm{LPW}=$ lens power (calculated).

\section{Results}

Age, sex, duration of diabetes, $\mathrm{HbA}_{1 \mathrm{c}}$, blood glucose, and intrapair differences in duration of diabetes, reading/close work, and education level are shown in Table 2, according to the three different zygosity groups. There were six MZ pairs concordant for diabetes, all DZss pairs were discordant, and one DZos pair was concordant for diabetes.

Some of the twins had high values of $\mathrm{HbA}_{1 \mathrm{c}}$ and blood glucose, especially in the DZos group, where the intrapair differences were highest. In most cases both $\mathrm{HbA}_{1 \mathrm{c}}$ and blood glucose were high within the same twin (correlation coefficient between $\mathrm{HbA}_{1 \mathrm{c}}$ and blood glucose, $r=0.62, \mathrm{p}<0.001, \mathrm{n}=88$ ). In order to search for short term fluctuation in refraction caused by current level of metabolic control, the differences between twins' own glasses and the measured refraction was calculated and correlated with the measured values of $\mathrm{HbA}_{1 \mathrm{c}}$ and blood glucose. No statistically significant correlations were found.

The intrapair differences in the possible confounders: reading habits, close work, and level of education were very small in the $M Z$ group. In the DZss group four pairs had differ- ences greater than one category, and in the DZos group eight pairs had differences greater than one category. Given the small sizes of the groups, however, we found no reason to adjust for the possible confounding effects.

In Table 3, we have summarised the measured values of refraction and its components looking at the twins as diabetic and nondiabetic individuals. The results are shown for right eyes and left eyes separately. The ultrasonometric measurements are not complete because two of the younger twins did not cooperate with all measurements. Refraction was not normally distributed, thus both median and mean values are listed. The median and mean refractive values were more myopic in the diabetic than in the non-diabetic group ( $p<0.05$, Mann-Whitney test). Mean anterior chamber depth was slightly shallower in the diabetic group, and the mean lens thickness correspondingly larger in the diabetic group, $(\mathrm{p}<0.05$ for right eye and $\mathrm{p}=0.1$ for left eye, Mann-Whitney test). The mean of calculated lens power was, like lens thickness, greater in the diabetic group than in the non-diabetic group $(\mathrm{p}<0.05$, Mann-Whitney

Table 4 Spearman correlation coefficients ( $r$ ) between intrapair differences in duration of diabetes and intrapair differences in refraction and its components, in each of the three zygosity groups

\begin{tabular}{|c|c|c|c|c|c|c|c|c|c|c|}
\hline & \multirow[b]{2}{*}{ Eye } & \multicolumn{3}{|c|}{$M Z$} & \multicolumn{3}{|c|}{$D Z s s$} & \multicolumn{3}{|c|}{ DZos } \\
\hline & & $n$ & $r$ & $p$ & $n$ & $r$ & $p$ & $n$ & $r$ & $p$ \\
\hline \multirow[t]{2}{*}{ Refraction } & $\mathrm{R}$ & 16 & 0.39 & 0.135 & 14 & -0.76 & 0.002 & 15 & -0.14 & 0.612 \\
\hline & $\mathrm{L}$ & 16 & 0.46 & 0.075 & 14 & -0.65 & 0.012 & 15 & -0.11 & 0.703 \\
\hline \multirow[t]{2}{*}{ Axial length } & $\mathrm{R}$ & 15 & -0.42 & 0.121 & 13 & 0.66 & 0.014 & 15 & -0.01 & 0.960 \\
\hline & $\mathrm{L}$ & 15 & -0.45 & 0.092 & 13 & 0.62 & 0.024 & 15 & -0.18 & 0.516 \\
\hline \multirow[t]{2}{*}{ Corneal curvature } & $\mathrm{R}$ & 16 & 0.16 & 0.549 & 14 & 0.48 & 0.094 & 15 & 0.05 & 0.879 \\
\hline & L & 16 & 0.26 & 0.333 & 14 & 0.48 & 0.094 & 15 & 0.24 & 0.426 \\
\hline \multirow[t]{2}{*}{ Anterior chamber depth } & $\mathrm{R}$ & 15 & -0.57 & 0.026 & 13 & -0.43 & 0.146 & 15 & -0.24 & 0.383 \\
\hline & $\mathrm{L}$ & 15 & -0.57 & 0.028 & 13 & -0.28 & 0.415 & 15 & -0.32 & 0.240 \\
\hline \multirow[t]{2}{*}{ Lens thickness } & $\mathrm{R}$ & 15 & 0.75 & 0.001 & 13 & 0.57 & 0.041 & 15 & 0.56 & 0.029 \\
\hline & $\mathrm{L}$ & 15 & 0.65 & 0.008 & 13 & 0.60 & 0.031 & 15 & 0.62 & 0.013 \\
\hline \multirow[t]{2}{*}{ Lens power } & $\mathrm{R}$ & 15 & -0.25 & 0.376 & 13 & 0.34 & 0.263 & 14 & -0.26 & 0.375 \\
\hline & $\mathrm{L}$ & 15 & 0.09 & 0.742 & 13 & 0.38 & 0.194 & 14 & -0.44 & 0.114 \\
\hline
\end{tabular}


Table 5 Discordant $M Z$ twins $(n=10)$. Spearman correlation coefficients $(r)$ between intrapair differences in duration of diabetes and intrapair differences in refraction, axial length, lens thickness, and lens power

\begin{tabular}{llrrc}
\hline Discordant $M Z$ & Eye & $n$ & \multicolumn{1}{l}{$r$} \\
\hline Refraction & $\mathrm{R}$ & 10 & 0.35 & 0.32 \\
& $\mathrm{~L}$ & 10 & 0.53 & 0.12 \\
Axial length & $\mathrm{R}$ & 9 & -0.52 & 0.15 \\
& $\mathrm{~L}$ & 9 & -0.78 & 0.01 \\
Lens thickness & $\mathrm{R}$ & 9 & 0.93 & $<0.001$ \\
& $\mathrm{~L}$ & 9 & 0.88 & $<0.001$ \\
Lens power & $\mathrm{R}$ & 9 & -0.38 & 0.31 \\
& $\mathrm{~L}$ & 9 & -0.28 & 0.46 \\
\hline
\end{tabular}

test). The mean of corneal curvature and axial length did not differ in the two groups.

The influence of duration of diabetes on refraction and its components has been estimated in each of the three zygosity groups. In Table 4, the correlation coefficients between intrapair differences in duration of diabetes, and intrapair differences in refraction, and each of its components are shown.

In the $\mathrm{MZ}$ group we found a tendency of positive correlation between intrapair differences in duration of diabetes, and intrapair differences in refraction - that is, a shift in hyperopic direction, with increasing duration of diabetes in the $\mathrm{MZ}$ group. In the DZss group, we found the opposite result; a statistically significant shift in myopic direction, with increasing duration of diabetes. In the DZos group, no correlation between duration of diabetes and refraction was seen.

There was a negative correlation between axial length and duration of diabetes in the $\mathrm{MZ}$ group, which did not reach statistical significance. In the DZss group axial length was statistically significantly positively correlated with duration of diabetes - in other words in the DZss group, but not in the MZ group, the axial lengths were longer in the twins with longer duration of diabetes, corresponding to the more myopic refractive power. In the DZos group, no correlation between axial length and duration of diabetes was seen.

Lens thickness was statistically significantly positively correlated with duration of diabetes in all the zygosity groups, with strongest correlation in the $M Z$ group. Lens power was not significantly correlated with duration of diabetes in any of the groups. Corresponding to increasing lens thickness, anterior chamber depth was negatively correlated at significant

Table 6 Spearman correlation coefficients ( $r$ ) of refraction versus lens thickness, refraction versus lens power, and lens thickness versus lens power in the group of twins with (+) IDDM and the group of twins without (-) IDDM

\begin{tabular}{lllll}
\hline & Eye & $n$ & $r$ & $p$ \\
\hline + IDDM: & & & & \\
Refraction $v$ lens thickness & $\mathrm{R}$ & 51 & -0.16 & 0.27 \\
& $\mathrm{~L}$ & 51 & -0.15 & 0.30 \\
Refraction $v$ lens power & $\mathrm{R}$ & 50 & -0.15 & 0.30 \\
& $\mathrm{~L}$ & 50 & -0.03 & 0.82 \\
Lens thickness $v$ lens power & $\mathrm{R}$ & 50 & 0.47 & 0.001 \\
& $\mathrm{~L}$ & 50 & 0.49 & 0.000 \\
- IDDM: & $\mathrm{R}$ & 37 & 0.34 & 0.04 \\
Refraction $v$ lens thickness & $\mathrm{L}$ & 37 & 0.40 & 0.02 \\
Refraction $v$ lens power & $\mathrm{R}$ & 36 & 0.26 & 0.12 \\
& $\mathrm{~L}$ & 36 & 0.33 & 0.04 \\
Lens thickness $v$ lens power & $\mathrm{R}$ & 36 & 0.49 & 0.003 \\
& $\mathrm{~L}$ & 36 & 0.48 & 0.003 \\
\hline
\end{tabular}

level in the $M Z$ group, showing the same tendencies in the other two groups, although not reaching significant levels.

In the MZ group, there are six pairs concordant for diabetes and 10 pairs discordant (Table 5), and the mix of twins with diabetes and twins without diabetes in this design could be objected to. We therefore recalculated the correlation coefficients for refraction, axial length, lens thickness, and lens power using only the 10 available discordant MZ pairs. There is an indication of an association between duration of diabetes and shorter axial lengths, as seen from the high negative correlation coefficients between intrapair differences in axial length and duration of diabetes. Intrapair differences in lens thickness became even more highly positively correlated with intrapair differences in duration of diabetes only using the discordant $M Z$ pairs, while there was a tendency to negative correlation of intrapair differences in lens power.

To further evaluate the influence of the lens on refraction, we calculated the Spearman correlation coefficients between lens thickness and refraction; lens power and refraction, and lens thickness and lens power in the group of diabetic twins and the group of non-diabetic twins (Table 6). In the group of diabetic twins there was a slight negative correlation between lens thickness and refraction, in other words more myopic refraction with thicker lenses, although this correlation was not significant. In the group of non-diabetics there was a statistically significant positive correlation between lens thickness and refraction. The same tendencies were seen concerning lens power and refraction, and there were high correlation coefficients between lens thickness and lens power in both the diabetic and the nondiabetic group.

\section{Discussion}

There is no general agreement about the influence of diabetes mellitus on refraction. Lack of standardised definitions of refractive errors, non-uniform methods of measuring refraction, and diverging classifications of diabetes mellitus make it difficult to compare the results of previous studies. The amount of reading and close work and education level as well as regulation of diabetes may confound the comparison of refraction in people with and without diabetes. A study of monozygotic twinsdiscordant for insulin dependent diabetes mellitus - would be the ideal design to control for confounders ${ }^{33}$; we have a nearly perfect match, not only on age and sex, but also on genes and many environmental factors. However, it is difficult to find an appropriate number of discordant monozygotic twin pairs, especially because the age adjusted concordance rates for IDDM in $M Z$ twins is high $(0.7){ }^{30}$ Using the intrapair differences in duration of diabetes makes it possible to also obtain information from the concordant $\mathrm{MZ}$ pairs.

As seen in Table 2 the $M Z$ group is nearly perfectly matched concerning the possible confounders-reading/close work and education; in the DZss group four pairs differ and in 
the DZos group eight pairs differ. The levels of $\mathrm{HbA}_{1 \mathrm{c}}$ and blood glucose are high in some of the twins; thus, in the $M Z$ group in most of the cases the values are high in both of the co-twins, making the results in the $\mathrm{MZ}$ group more reliable than in the other two groups. Our analysis of the relations between power of glasses and actual measured refractive power in cycloplegia and indicators of glycaemic control suggest that the results of our study have not been influenced by acute dysregulation of diabetes.

In the $M Z$ group we found a tendency for negative correlation of axial length with duration of diabetes, and a corresponding tendency for positive correlation of refractive values with duration of diabetes. In the DZss group the results are in the opposite direction; a positive correlation of axial length with duration of diabetes, and a corresponding negative correlation with refractive values.

Are the results of refraction and axial length in the $M Z$ group reliable and could they be explained? As a hypothesis, one might speculate whether the influence of diabetes during childhood would result in reduced growth of the eye in an axial direction with shorter eyes and refractive values in a more hyperopic direction as a consequence. To examine this further on our data, we selected the pairs with onset of diabetes before the age of 15 . We then calculated the intrapair differences in duration of diabetes before the age of 15 , and correlated these with intrapair differences in axial length in the $M Z$ group and the DZss group. We have now only six MZ pairs and five DZss pairs left; with correlation coefficients of $-0.1 /-0.4$ in the $M Z$ group and $-0.1 / 0.0$ in the DZss group. This does not allow us to draw any conclusions, but the tendency of a negative association between duration of diabetes and axial length is maintained in the $M Z$ group, and the tendency of a positive association between duration of diabetes and axial length has partly disappeared in the in the DZss group.

In addition to axial length, increased lens thickness and alteration of refractive index in the lens may play a role in the more permanent alterations of refraction. The refractive index of the lens cannot be measured directly, and cannot be calculated from our measurements, since we have not measured the curvatures of the lens. The calculated lens power is the best estimate of the refractive index of the lens we can obtain; it is directly proportional to refractive index and inversely proportional to radius of curvatures of the lens. Since lens thickness is inversely proportional to curvature radius of the lens, it is not surprising that lens thickness and lens power are highly positively correlated (Table 6). The increased lens thickness with increasing duration of diabetes would tend to give steeper lens curvatures and from geometric considerations tend to give more myopic refractions, ${ }^{25}$ which is supported by the results in Table 6. At the same time refractive index in the lens may be lower, affecting the refraction in a hyperopic direction. ${ }^{19}$ The tendency of a negative correlation between intrapair differences in lens power and intrapair differences in duration of diabetes, despite the highly positive correlation of lens thickness (Table 5), could be explained by lower refractive index in the lenses of the twins with diabetes compared with the twins without diabetes.

Among the 52 twins with diabetes, 31 had no retinopathy, 19 had non-proliferative retinopathy, and only two had developed proliferative retinopathy. Thus, in the present study we have not been able to investigate the possible relation between severity of diabetic retinopathy and refractive error.

In summary, we can conclude that our twin study showed diverging results of relations between refraction and duration of diabetes. Among $M Z$ twins we found a tendency of decreased axial length and, correspondingly, more hyperopic refractive values with increasing duration of diabetes. On the basis of our results we hypothesise that this could be a result of decreased growth of the eye in the axial direction before puberty, when influenced by diabetes, but our sample size is too small for definite conclusions, and could thus be a result of chance.

At the same time we found increased lens thickness and decreasing anterior chamber depth with increasing duration of diabetes. Increased lens thickness might be responsible for some of the more low degree myopic refraction observed in diabetic patients. The tendency of lower lens power among diabetics compared with non-diabetics might be explained by lowering of refractive index in the lens when influenced by diabetes.

Our findings show that insulin dependent diabetes mellitus may influence refraction of the eye on different levels. Visual complaints in younger diabetic patients with no or minimal retinopathy may be a result of refractive changes, which can be corrected simply by glasses or contact lenses. On the other hand, better glycaemic control in the early stages of diabetes could possibly minimise the refractive changes.

This study has been supported financially by the Danish Diabetes Association; the Danish Eye Research Foundation (Øjenfonden); and Hotelejer Carl Larsen og Hustru Nicoline Larsens Fond (Værn om Synet).

We also want to thank the twins for their kind cooperation.

1 Sorsby A, Sheridan M, Leary GA. Refraction and its components in twins. Medical Research Council Special Report Series. 303th edn. London: HMSO, 1962.

2 Lin LL, Chen CJ. Twin study on myopia. Acta Genet Med Gemellol Roma 1987;36:535-40.

3 Teikari JM, Kapiro J, Koskenvuo MK, Vannas A. Heritability estimate for refractive errors-a population-based samity estimate for refractive errors-a population-based
ple of adult twins. Genetic Epidemiol 1988;5:171-81.

4 Teikari J, Koskenvuo M, Kaprio J, O'Donnell J. Study of gene-environment effects on development of hyperopia: a study of 191 adult twin pairs from the Finnish Twin Cohort Study. Acta Genet Med Gemellol Roma 1990;39: 133-6.

5 Teikari JM, Kaprio J, Koskenvuo M, O’Donnell J. Heritability of defects of far vision in young adults - a twin study. Scand F Soc Med 1992;20:73-8.

6 Angi MR, Clementi M, Sardei C, Piattelli E, Bisantis C. Heritability of myopic refractive errors in identical and fraternal twins. Graefes Arch Clin Exp Ophthalmol 1993;231: $580-5$.

7 Curtin B. The myopias. Basic science and clinical management. Philadelphia: Harper and Row, 1985.

8 McBrien NA, Millodot M. A biometric investigation of late onset myopic eyes. Acta Ophthalmol 1987;65:461-8.

9 Grosvenor T, Scott R. Three year changes in refraction and its components in youth - onset and early adult onset myopia. OptomVis Sci 1993;70:677-83. 
10 Fledelius HC. Adult onset myopia-oculometric features. Acta Ophthalmol Scand 1995;73:397-401.

11 Sorsby A, Leary GA. A longitudinal study of refraction and its components during growth. Med Res Coun Spec Report Ser No 309. London: HMSO, 1970.

12 Mantyjarvi M. Myopia and diabetes. A review. Acta Ophthalmol Suppl 1988;185:82-5.

13 Fledelius HC, Fuchs J, Reck A. Refraction in diabetics during metabolic dysregulation, acute or chronic. With special reference to the diabetic myopia concept. Acta Ophthalmol (Copenh) 1990;68:275-80.

14 Gwinup G, Villarreal A. Relationship of serum glucose concentration to changes in refraction. Diabetes 1976;25:2931.

15 Saito Y, Ohmi G, Kinoshita S, Nakamura Y, Ogawa K, Harino S, et al. Transient hyperopia with lens swelling at

16 Planten JT, Kooijman AC, de Vries B, Woldringh JJ. Pathological-optic approach of cataract and lens. Ophthalmologica 1978;176:331-4.

17 Eva PR, Pascoe PT, Vaughan DG. Refractive change in hyperglycaemia: hyperopia, not myopia. $\mathrm{Br} \mathcal{F}$ Ophthalmol 1982;66:500-5.

18 Fledelius HC. Refractive change in diabetes mellitus around onset or when poorly controlled. A clinical study. Acta Ophthalmol (Copenh) 1987;65:53-7.

19 Varma SD, El-Aguizy HK, Richards RD. Refractive change in alloxan diabetic rabbits control by flavonoids I. Acta Ophthalmol 1980;58:748-59.

20 Fledelius HC. Is myopia getting more frequent? A cross-sectional study of 1416 Danes aged 16 years+. Acta Ophthalmol (Copenh) 1983;61:545-59.

21 Fledelius HC. Myopia and diabetes mellitus with special reference to adult-onset myopia. Acta Ophthalmol (Copenh) 1986;64:33-8.
22 Sjølie AK. Ocular complications in insulin-treated diabetes mellitus. Acta Ophthalmol (Copenh) 1985,suppl 172.

23 Rand LI, Krolewski AS, Aiello LM, Warram JH, Baker RS, Maki T. Multible factors in the prediction of risk of proliferative diabetic retinipathy. $N$ Engl F Med 1985;313:1433-8. 24 Jain IS, Luthra CL, Das T. Diabetic retinopathy and its rela-
tion to errors of refraction. Arch Ophthalmol 1967;77:5960

25 Fledelius HC, Miyamoto K. Diabetic myopia-is it lens-induced? An oculometric study comprising ultrasound lects 73 .

26 Sparrow JM, Bron AJ, Brown NA, Neil HA. Biometry of the crystalline lens in early-onset diabetes. $\mathrm{Br} \mathcal{F}$ Ophthalmol 1990;74:654-60.

27 Sparrow JM, Bron AJ, Phelps Brown NA, Neil HA. Biometry of the crystalline lens in late onset diabetes: the mportance of diabetic type. Br f Ophthalmol 1992;76:42833.

28 Løgstrup N, Sjølie AK, Kyvik KO, Green A. Lens thickness and insulin dependent diabetes mellitus: a population based twin study. Br 7 Ophthalmol 1996;80:405-8.

29 Kyvik KO, Green A, Beck-Nielsen H. The New Danish Twin Register: establishment and analysis of twinning Twin Register: establishment and and
rates. Int $\mathcal{f}$ Epidemiol 1995;24:589-96.

30 Kyvik KO, Green A, Beck-Nielsen $\mathrm{H}$. Concordance rates of insulin dependent diabetes mellitus: a population based study of young Danish twins. BMF 1995;311:913.

31 Olsen T. Catrefract. PC Data 1992-94. Denmark.

32 Olsen T, Thim K, Corydon L. Theoretical versus SRK I and SRK II calculation of intraocular lens power. $\mathcal{F}$ Cataract Refract Surg 1990;16:217-25.

33 Schwartz JT. Twin studies in ophthalmology. Am f Ophthalmol 1968;66:323-7. 